\title{
Karakter Visual Keindonesiaan dalam Iklan Cetak di Indonesia
}

\author{
Didit Widiatmoko Suwardikun
}

Program Studi Desain Komunikasi Visual

Fakultas Senirupa \& Desain-ITB

Email: diditw@bdg.centrin.net.id

\begin{abstract}
Many have tried to explore the unified identity character of an Indonesian, arousing certain tribal cultures to visually represent "Indonesian" on apparent bestowed upon Indonesia as a nation of multi-cultures. This is clearly be seen in advertisements where the expressed visuals represent periods, societal forms, political, and economical situation according to the allotted time and space. Thus, visuals on advertisements may serve as clues to understand the significance of expressions as "Indonesian" out of the memory of how things were and were done and therefore ought to be done. This study explores visuals from the advertisements of the past to understand the spirit of Indonesia as a nation for the purpose of tomorrow. The study looked into visuals of the advertisements from the Dutch colonial era, Japanese occupation period, the birth of a nation in 1950s, the new order (1970s-1990s), and end with those of reform order (2000s); in order to portray "Indonesian" in terms of figure, behavior, and attitude of a nation. The paper discusses visuals of the past to model the present and future of an "Indonesian".
\end{abstract}

Keywords: identity; visual character; advertisement.

\section{$1 \quad$ Pendahuluan}

Dunia visual dikelilingi oleh berbagai gambaran-gambaran visual (visual images) yang berkembang setiap saat, dan gambaran visual yang paling agresif tersebut adalah bentuk iklan cetak. Mulai dari bangun pagi hingga berangkat tidur dimalam hari, bisa masyarakat kerap bersentuhan dengan iklan. Iklan-iklan tersebut mempersuasi pengamat sehingga secara tidak sadar telah dipengaruhi iklan. Hal itu seperti pemilihan pakaian, jam-tangan, sepatu dan demikian juga barang konsumsi seperti makanan, minuman dan rokok, dan ketika membelinya, benda-benda itu secara tak sadar sebenarnya mengacu pada merek tertentu yang pernah diiklankan.

Iklan diperlukan produsen untuk mengumumkan produknya dan juga diperlukan konsumen untuk mengetahui informasi mengenai produk yang dibutuhkan. Setiap hari berbagai produk consumer goods dikomunikasikan baik melalui iklan dimedia massa, media luar ruang maupun melalui kemasan yang 
menarik. Periklanan modern di Indonesia diperkirakan hadir pada awal abad 20 [1], semasa penjajahan Belanda, pada masa itu mulailah iklan atau advertentie untuk barang-barang import bagi orang Belanda di tanah jajahannya. Kemudian berkembang pesat ketika masa kemerdekaan dan masa pembangunan industri di Indonesia [2].

Bahasan dalam tulisan ini adalah ilustrasi atau penggambaran tokoh atau figur dalam iklan, karena ilustrasi dalam hal ini berperan sebagai alat persuasi visual. Berbagai gaya persuasi visual yang ditampilkan dalam iklan, ada yang menggunakan nilai-nilai lokal, namun ada pula yang menggunakan nilai-nilai global.

Iklan dapat dipahami sebagai pesan dalam bentuk image yang terdiri dari visual dan verbal. Iklan yang efektif terjadi sinergi diantara unsur headline, copy dan ilustrasi, maka headline, body copy, dan ilustrasi bekerjasama untuk menarik perhatian konsumen dan menjadikan hal yang terpenting dari pesan iklan, seringkali sebagai pembuka pintu yang dapat membuat pengamat bersuasana hati mau menerima ide-ide baru yang disampaikan iklan [3].

Iklan dan periklanan tidak hanya bertujuan menawarkan dan mempengaruhi masyarakat untuk membeli barang atau jasa, tetapi juga turut menularkan nilainilai dan ideologi tertentu yang terpendam didalamnya. Ideologi barat seperti gender, cowboy, budaya mengadu nasib, desakralisasi etnik, degradasi norma ketimuran, demitosisasi, dan hedonisme, hal-hal semacam ini dalam iklan dikemas secara simbolik dan divisualisasikan seolah semuanya menjadi masuk akal.

Kebudayaan merupakan sesuatu yang sangat relatif, dapat berubah sesuai jamannya. Budaya lokal sebagai hasil akulturasi dan asimilasi, sebagai karakter khas daerah terbentuk melalui proses yang sangat lama dan panjang menjadi kebudayaan yang otentik dari suatu daerah. Terbentuknya kebudayaan ini melalui proses meniru, menciptakan serta mengembangkan hasil kebudayaan tersebut. Unsur alam dari suatu kawasan serta karakter fisik dan tradisi dari masyarakatnya dapat menjadi karakter lokal. Negara-negara seperti Jepang, India, dan Thailand sudah mulai kembali ke nilai-nilai lokal mereka, tetapi yang cukup mengherankan, Indonesia masih belum banyak menggali nilai-nilai kebudayaannya sendiri untuk dimanfaatkan sebagai ciri atau identitas khususnya pada bidang periklanan. Pada saat ini orang barat mulai menengok ke budaya timur, namun orang Indonesia tetap saja silau dengan budaya barat. Iklan dengan karakter lokal dalam tiga tahun terakhir ini menjadi sering dibicarakan dalam forum periklanan seolah masyarakat periklanan menjadi tergugah untuk mempertanyakan budaya lokal [4], yaitu yang berkaitan dengan karakter keindonesiaan dalam periklanan Indonesia, karena dengan pemahaman 
terhadap budaya inilah yang akan menghasilkan simbol-simbol sebagai dasar antara pengiklan, produk dan penerima pesan. Budaya lokal memainkan peran penting dalam proses penyampaian pesan pada khalayak.

Karakter Indonesia sering muncul sebagai perdebatan ketika bangsa Indonesia mencari identitas untuk mendirikan eksistensinya sebagai sebuah bangsa yang bersatu. Dalam sepuluh tahun terakhir sejak tahun 1998, berbagai krisis melanda Indonesia sehingga dalam wacana politik banyak orang mempertanyakan perihal keindonesiaan. Sri Sultan [5], mengungkapkan Indonesia sedang menghadapi berbagai tantangan besar seperti menguatnya budaya konsumerisme dan kekerasan, menipisnya kesadaran pluralisme dan semangat kebangsaan, tingginya kemiskinan dan pengangguran, dan ketertinggalan dari negara-negara Asia Tenggara menjadi subordinat bagi kepantingan asing. Identitas dan karakter Indonesia timbul lagi menjadi bahan diskusi. Tokoh gerakan reformasi 1998 Amien Rais [6] menegaskan bahwa masalah besar yang dihadapi Indonesia saat ini adalah mengapa kita terus saja miskin, terbelakang, dan tercecer dalam derap kemajuan bangsa-bangsa lain. Indonesia telah terseret menjadi sekadar subordinat atau agen setia bagi kepentingan asing. Identitas keindonesiaan secara beruntun menjadi perbincangan di negeri ini. Jika Indonesia memiliki karakter yang beradab dan kuat maka akan bangsa ini akan diperhitungkan sebagai representasi dari kebesaran, keagungan, kehormatan. Artinya, menjaga kedaulatan bangsa terhadap penggerusan oleh bangsa asing dan membangun sendi-sendi kehidupan kebangsaan yang fundamental dan sistematis sebagai bagian dari proses "Indonesian character building".

Indonesia pernah menjadi bangsa yang paling disegani di Asia tenggara, negaranegara tetangga menaruh hormat terhadap Indonesia, karena kekuatan karakter dan identitas bangsa ini, yang terbentuk oleh cita-cita yang sama akan rasa kebersatuan dan kebersamaan akan suatu negara.

Kapankah itu terjadi?, dapat dilihat dalam perjalanan sejarah visualisasi karakter Indonesia dalam iklan yang pernah diterbitkan di Indonesia.

\section{$2 \quad$ Metoda}

Untuk memetakan pola visualisasi iklan digunakan pendekatan sejarah. Menurut Kuntowijoyo [7] hakikat ilmu sejarah sangat perlu diketahui justru agar kita mengetahui betul bahwa ilmu sejarah mempunyai raison d'etre sendiri, dengan periodisasi maka dapat diketahui pola antara satu periode dengan periode lainnya, setelah diketahui ada ciri khas pada suatu kurun sejarah. Dari pendekatan ini dapat dirumuskan pola visualisasi karakter Indonesia dalam iklan pada setiap periode sejarah. Untuk memahami makna 
budaya perlu dikonstruksikan hal-hal yang berkaitan dengan pembentukan budaya itu sendiri. Makna mungkin dapat dikonstruksi secara sosial, tetapi mereka dikonstruksi dalam jarak yang dibolehkan oleh kerangka institusional dan didasari oleh makna dan formulasi masa lalu, suatu konsep yang dikenal dengan historicity. Makna kemudian di rekonstruksi sebagaimana konsumer menggunakan mereka dalam situasi sosial yang khas yang muncul dalam artikulasi-artikulasi dalam data.

Untuk memberi penjelasan bagaimana visualisasi figur Indonesia pada iklan cetak yang diterbitkan pada dekade 1950 -an dan bagaimana pola visualisasinya sehingga membentuk budaya Indonesia, dengan menganalisis gambar figur manusia dapat memberikan gambaran tentang pola kehidupan manusia dan budayanya, seperti yang dikemukakan oleh Collier, bahwa gambar-gambar dari orang-orang yang sedang berinteraksi memberikan peluang pada kita untuk mengukur, mengkualifikasi dan membandingkan, dan pengukuran seperti ini dapat berperan lebih jauh yaitu dapat untuk mendefinisikan pola kehidupan dan budaya pada suatu masyarakat [2]. Gambar-gambar yang dimaksud dalam analisis iklan-iklan ini adalah bagaimana penggambaran ilustrasi, posisi figur dalam layout, cara berpakaian, gestur, cara bersikap, cara memandang, bentuk wajah.

\section{Bahasan dengan pendekatan historis}

\begin{tabular}{|c|c|c|c|c|c|}
\hline \multicolumn{6}{|c|}{ HISTORICAL PERIODIZATION } \\
\hline \multicolumn{6}{|l|}{ POLITIC } \\
\hline $\begin{array}{c}1615-1940 \\
\text { V O C - Dutch }\end{array}$ & $\begin{array}{l}1942-1945 \\
\text { Japanese } \\
\text { occupation }\end{array}$ & $\begin{array}{c}1945-1950 \\
\text { Revolution } \\
\text { of } \\
\text { Independence }\end{array}$ & $\begin{array}{l}\text { 1950-1957 } \\
\text { Parliamentary } \\
\text { Democracy }\end{array}$ & $\begin{array}{l}\text { 1957-1965 } \\
\text { Guided } \\
\text { Democra cy }\end{array}$ & $\begin{array}{cc}1965-1998 & 2000 \text { 's } \\
\text { New Order } & \begin{array}{c}\text { The new form } \\
\text { of Colonialism: } \\
\text { "Globalization" }\end{array}\end{array}$ \\
\hline \multicolumn{6}{|l|}{ ADVERTISING } \\
\hline $\begin{array}{l}\text { Marketing for } \\
\text { Imported goods }\end{array}$ & $\begin{array}{l}\text { Propaganda } \\
\qquad 3 \mathrm{~A}\end{array}$ & & $\begin{array}{l}\text { Local Adv. Ag } \\
\text { Indonesian } \mathrm{F}\end{array}$ & $\begin{array}{l}\text { encies. } \\
\text { Product }\end{array}$ & $\begin{array}{l}\text { Foreign Investment: } \\
\text { International Agencies } \\
\text { and Foreign Products }\end{array}$ \\
\hline $\begin{array}{l}\text { Indigene as } \\
\text { an Object }\end{array}$ & $\begin{array}{l}\text { Indonesians } \\
\text { began } \\
\text { subject }\end{array}$ & & $\begin{array}{l}\text { Emerged Ind } \\
\text { figures \& Che }\end{array}$ & $\begin{array}{l}\text { onesian } \\
\text { aracters }\end{array}$ & $\begin{array}{l}\text { Indonesian figures, but } \\
\text { Western behaviors } \\
\text { Western visual idioms }\end{array}$ \\
\hline \multicolumn{6}{|c|}{ SOCIAL CONDITION } \\
\hline $\begin{array}{l}\text { "Ideal is } \\
\text { being Dutch" }\end{array}$ & $\begin{array}{l}\text { miseries, } \\
\text { war situation, } \\
\text { proudness as } \\
\text { an asian nation }\end{array}$ & & $\begin{array}{l}\text { National Ide } \\
\text { proudness } \\
\text { being Indon }\end{array}$ & $\begin{array}{l}\text { ntity : } \\
\text { s as }\end{array}$ & $\begin{array}{l}\text { Ideal is being } \\
\text { "Western" }\end{array}$ \\
\hline
\end{tabular}

Gambar 1 Periodisasi Sejarah (berdasarkan teori pada buku: Kuntowijoyo [7], Riclef [8]; Setiyono [9]). 
Iklan-iklan yang diambil sebagai sampling adalah iklan-iklan produk konsumen berilustrasi yang berjumlah sekitar 400 buah iklan yang dari koran dan majalah dari perioda tahun 1900-an, 1940-an, 1950-an, 1970-an dan tahun 2000-an sesuai dengan periodisasi kesejarahan. Iklan-iklan yang terpilih memiliki signikasi untuk membentuk pola visualisasi dalam setiap perioda.

Periklanan masuk ke Indonesia sejak jaman kolonial Belanda yang menurut sejarah periklanan Indonesia ditandai dengan terbitnya Bataviasche Nouvelles pada tanggal 8 Agustus 1744, dapat dikatakan sebagai lembaran iklan, karena sebagian besar berita yang dimuat adalah iklan perdagangan pelelangan dan pengumuman pemerintah VOC [9]. Pada awalnya iklan-iklan surat kabar digunakan untuk kepentingan penjualan produk-produk konsumen dari Belanda kepada orang-orang Belanda di tanah jajahannya, kemudian juga ditujukan untuk khalayak pribumi, karena diberlakukannya politik balas budi atau politik "Ethis" oleh pemerintah Hindia Belanda pada awal 1900an, ditandai dengan mulai munculnya golongan pribumi terpelajar yang berbahasa Belanda, sehingga ada dugaan bahwa dalam iklan juga digunakan unsur-unsur yang berciri pribumi, selanjutnya media surat kabar dan periklanan berkembang pesat hingga mendatangkan pelukis-pelukis iklan dari Eropa. Dari catatan sejarah periklanan, sejak jaman Belanda masyarakat di pulau Jawa mulai mengadaptasi adat Belanda, diantaranya adalah kebiasaan toast dengan minuman keras pada upacara resmi di keraton, diawali dari raja dan para bangsawan tinggi kemudian diikuti oleh bangsawan-bangsawan dengan tingkat yang lebih rendah dan seterusnya, sehingga pada jaman itu sesuatu yang ideal adalah menjadi Belanda. Iklan berperan dalam perubahan masyarakat di Jawa pada masa Kolonial [10].

Pada tahun 1942 Pendudukan pasukan Jepang di Indonesia, [9] dengan slogan 3A: Jepang Pelindung Asia, Cahaya Asia, Pemimpin Asia, sebagai kekuatan ekonomi baru bahkan mulai menggunakan media periklanan untuk menanamkan pengaruh politiknya, baik terhadap penduduk bumiputera maupun Tionghoa dan Eropa. Menurut Riclef [8], untuk memusnahkan pengaruh barat (Belanda), pihak Jepang melarang pemakaian bahasa Belanda dan bahasa Inggris serta menggantikannya dengan penggunaan bahasa Jepang. Hal ini berlangsung dari tahun 1942 sampai 1945. Menurut buku sejarah Pers di Indonesia, di zaman Jepang, pers memang hanya digunakan untuk kepentingan propaganda balatentara Dai Nippon, guna menunjang usaha-usaha perjuangannya. Surat kabar yang boleh terbit juga sangat dibatasi, dan semua berada di bawah pengawasan ketat penguasa militer [11]. Dalam media cetak koran dan majalah selalu ada artikel pelajaran bahasa Jepang untuk rakyat Indonesia, namun ternyata tidak mudah memaksa mengajarkan bahasa asing baru kepada bangsa Indonesia, maka penggunaan bahasa Indonesia menjadi lebih marak. Di jaman penjajahan Jepang masyarakat Indonesia diharuskan mengikuti upacara "menghormat Kaisar" yaitu berbaris dan membungkuk 
kearah negara Jepang dalam kondisi terik matahari. Bahkan teater untuk tontonan rakyatpun menampilkan tentang fragmen-fragmen interaksi masyarakat Indonesia dengan pasukan Jepang salah satunya adalah berjudul "Toeroet dengan Amat". Tokoh Amat adalah orang Indonesia yang direkrut Jepang menjadi serdadu untuk berperang (majalah Jawa Baroe [12]), terlihat dari pakaian-pakaian pemainnya, yang pria memaki pakaian serdadu Jepang dan pemain wanita mengenakan kain-kebaya.

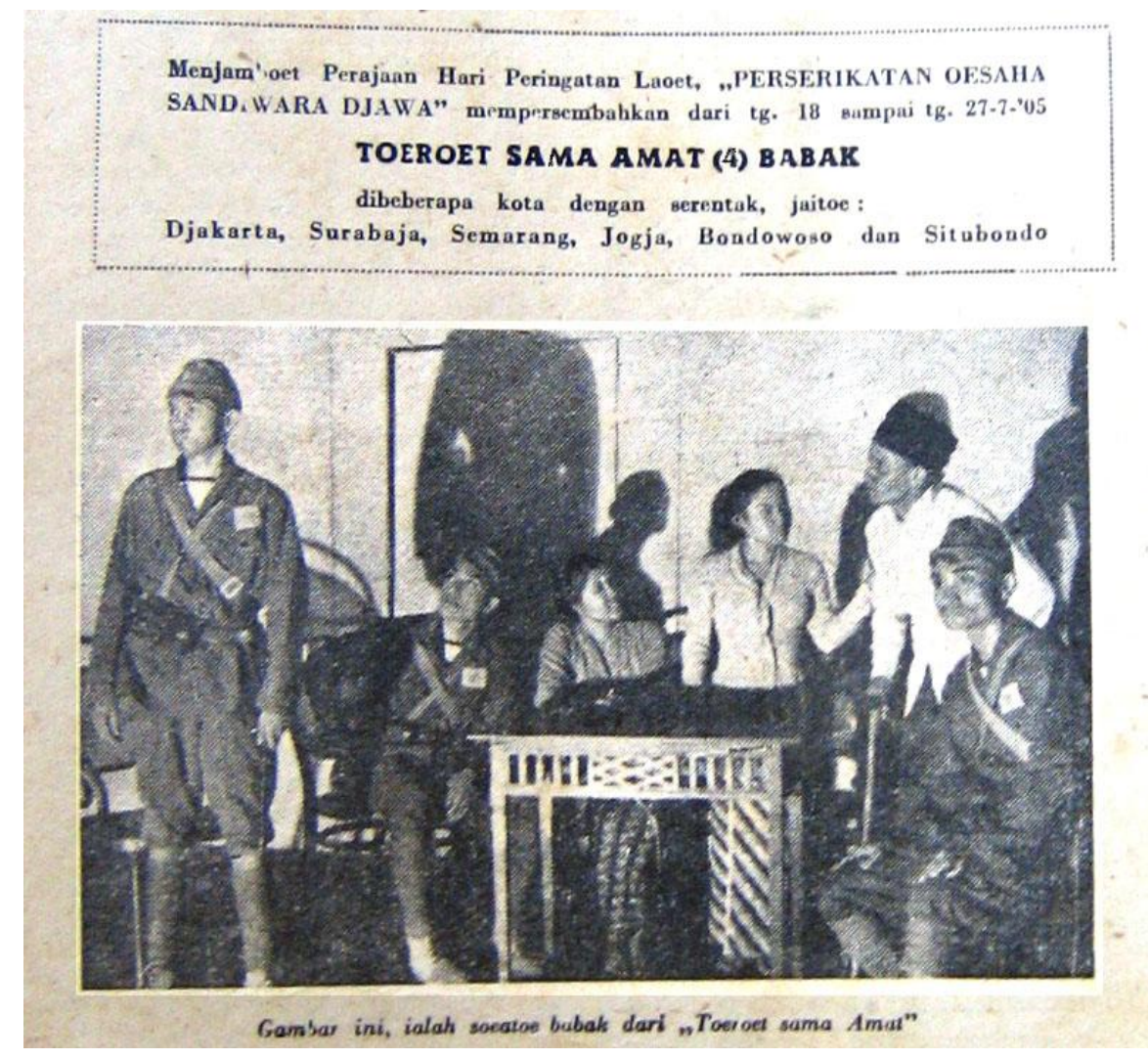

Gambar 2 Sandiwara Rakyat ( Majalah Jawa Baroe [12]).

Setelah Indonesia merdeka tanggal 17 Agustus 1945, Jepang kalah perang dan menyerah kepada sekutu. Jepang meninggalkan Indonesia dalam kondisi sudah terbentuknya semangat bangsa Asia yang anti Barat. Gejolak revolusi dan perang merebut dan mempertahankan kemerdekaan masih terus berlanjut hingga Belanda mengakui eksistensi Indonesia. Menurut Bondan Winarno [13] setelah Konferensi Meja Bundar di Den Haag tahun 1949, perekonomian dan periklanan di Indonesia mulai menggeliat kembali dari kehancuran seusai perang kemerdekaan. Tahun 1950an, rakyat Indonesia muali bangkit sedikit demi sedikit dari keterpurukan dan ketiadaan pasokan barang. Walaupun 
perusahaan-perusahaan besar milik Belanda seperti Unilever dan Borsumij masih ada, karena kurangnya pasokan maka rakyat pun mulai berdaya, barangbarang lokal pun mulai diproduksi dan diberi merek. Meniru konsep Mahatma Gandhi "Swadeshi" Indonesiapun mempunyai istilah "Berdikari" singkatan dari berdiri diatas kaki sendiri, maksudnya negara yang dibangun berdasarkan kemampuan sendiri, bukan hasil dari pinjaman dan pasokan negara lain. Dengan segala keterbatasan, namun bangsa Indonesia memiliki jatidiri yang kuat dan tercatat bahwa saat itu hutang luar negeri Indonesia masih sedikit. Tahun 1959 terjadi nasionalisasi perusahaan-perusahaan bekas milik Belanda dan orangorang Belanda pemiliknya pulang ke negerinya, sehingga banyak perusahaan iklan milik Belanda yang tutup, hal ini memberikan kesempatan pada pengusaha-pengusaha iklan lokal untuk berkembang. Mulai bermunculan media cetak lokal dan biro iklan lokal, iklan-iklan mulai muncul dengan visualisasi kebanggaan akan Indonesia.

Tahun 1965 terjadi pergantian kekuasaan negara dari Orde Lama (Soekarno) ke Orde Baru (Soeharto), yang pada tahun 1968 [9] mengambil kebijakan tentang Penanaman Modal Asing (PMA), berarti mulai dibukanya tameng perlindungan kepada usaha-usaha lokal yang pada saat itu baru mulai dan sedang berkembang, hingga tahun 1970an advertising agencies kelas dunia dari Amerika, Eropa, Australia dan Jepang mulai masuk dengan cara membuka perwakilan atau ber partner dengan perusahaan Indonesia. Mereka membawa budaya perusahaan dan konsep komunikasi dari negara asalnya dan mengaplikasikannya secara pragmatis kepada partner Indonesianya. Ada pula yang menyebut hal ini adalah awal dari era periklanan moderen di Indonesia. Kenyataannya Indonesia dianggap sebagai target market yang potensial bagi produk impor karena jumlah penduduknya yang sangat banyak dan sebagian besar masyarakat Indonesia terdiri dari orang-orang yang lugu atau rendah dalam taraf pendidikan dan cara berpikir. Terlebih lagi pertumbuhan perekonomian yang cerah sejak orde baru membuat pasar Indonesia menjadi penting bagi produk-produk mancanegara yang berasal dari Amerika, Jepang dan Eropa. Pada tahun 1976 misalnya, sekitar 73\% dari produk yang diiklankan adalah produk impor [14].

Dalam dunia periklanan Indonesia mulai terjadi friksi budaya, yang beberapa tokoh periklanan senior menyebutnya "sinkretisme" dalam periklanan. Untuk memasarkan barang dagangannya, importir dan distributor barang-barang produksi luar negeri yang semula menggunakan biro-biro iklan lokal, mereka mulai menggunakan biro-biro iklan sesuai dengan asal barang tersebut, seperti barang-barang Jepang di tangani oleh biro iklan asal Jepang, demikian juga dengan barang-barang Amerika dan Eropa. 


\section{$3 \quad$ Analisis Iklan Melalui Periodisasi}

\subsection{Periode Jaman Belanda}

Iklan-iklan cetak berilustrasi pada awal tahun 1900-an masih di dominasi oleh iklan produk impor, walaupun ada sedikit produk lokal seperti teh, tembakau dan obat. Ilustrasi iklan pada masa ini masih sedikit yang menampilkan figur dan karakter Indonesia. Jika pun ada, ilustrasi figur Indonesia ini diposisikan sebagai obyek atau pelengkap penderita, caranya dengan menampilkan secara frontal tampak depan atau tampak samping seperti meotret pesakitan, sedangkan figur Belanda pada saat itu ditampilkan dengan pandangan menyudut atau tidak frontal. Pesan-pesan verbal masih sekitar manfaat produk dan keuntungan menjadi penyalurnya. Pesan belum menjadi single minded message. Pada iklaniklan periode akhir penjajahan Belanda sudah mulai muncul ilustrasi dengan figur ber karakter Indonesia, namun belum banyak berperan sebagai subyek dalam iklan, figur-figur itu hanya bersifat memeragakan. Penggunaan bahasa sebagian masih menggunakan bahasa Belanda, kalaupun ada bahasa Indonesia masih tergolong bahasa Melayu-pasar.
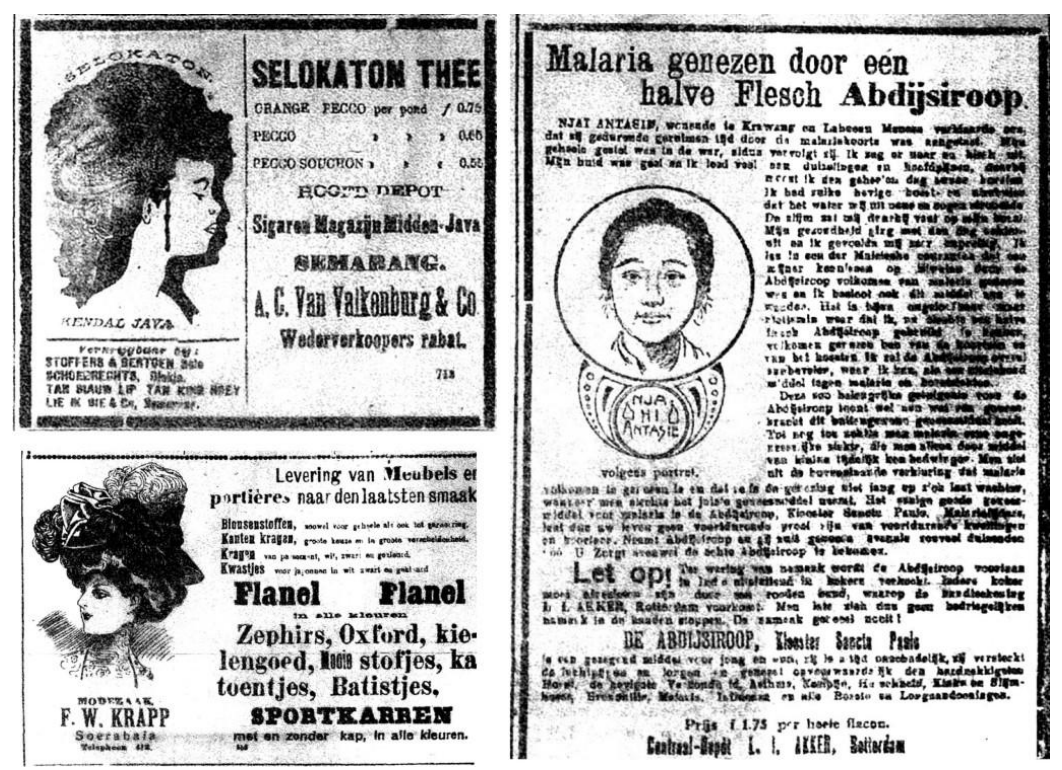

Gambar 3 Iklan cetak jaman penjajahan Belanda (De locomotief [15]).

\subsection{Periode Jaman Jepang}

Dalam iklan, yang sebelumnya menampilkan figur iklan berwajah Eropa di ganti dengan figur model iklan berwajah Jepang dengan sikap seperti figur Eropa, digambarkan dengan pandangan menyudut. Mulai muncul figur dan 
wajah Indonesia sebagai tokoh yang menjadi subyek atau tokoh dalam iklan. Contohnya iklan "Asia Katja Mata" mulai menggambarkan orang Indonesia sebagai "Tuan" yang mengenakan jas, dasi dan berkopiah, sedangkan tokoh mata-mata mengenakan jas dengan model topi yang sering dipakai orang Eropa. Slogan iklan bernuansa kewaspadaan akan perang. Ada pula iklan-iklan berslogan semangat Asia Timur Raya. Beberapa iklan menggunakan huruf Jepang, dan nama produsen menggunakan nama-nama Jepang. Dalam perioda ini figur berkarakter Indonesia mulai muncul sebagai subyek yaitu sebagai tokoh yang sedang berdialog mengenai suatu produk.
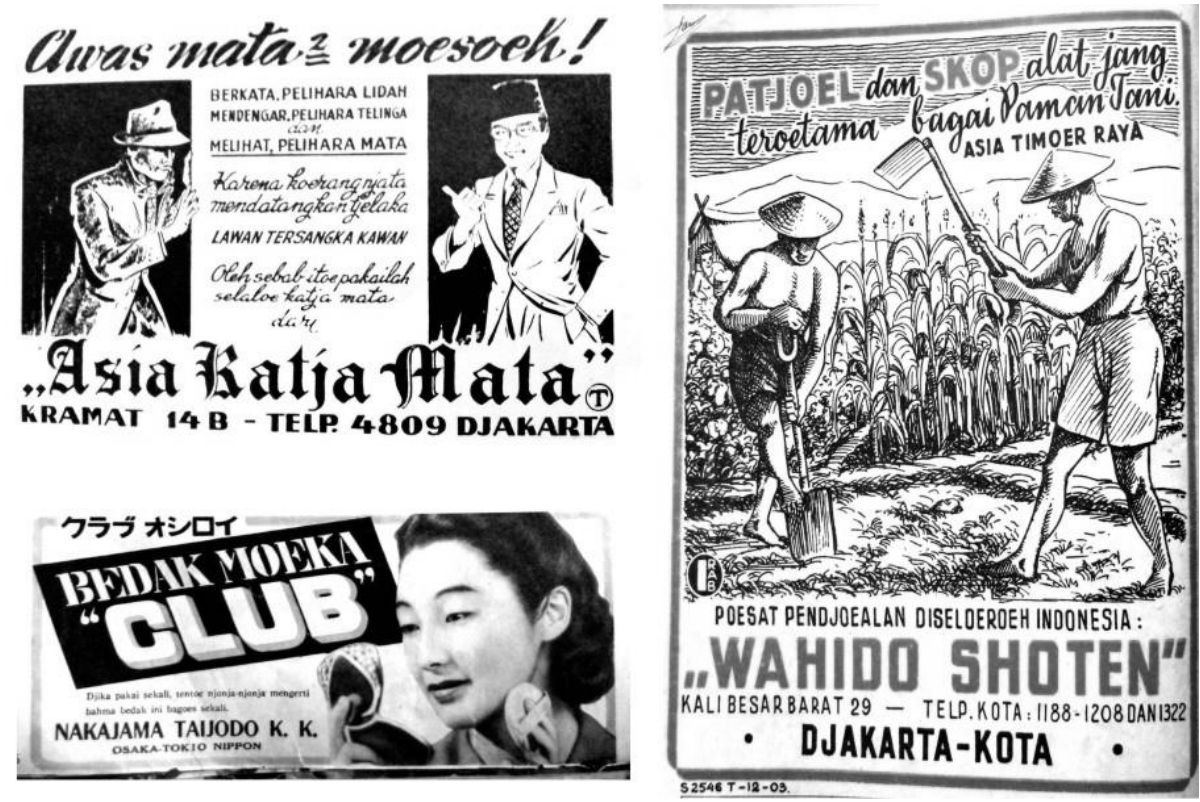

Gambar 4 Iklan cetak jaman penjajahan Jepang (Majalah Djawa Baroe [12]).

\subsection{Periode Tahun 1950-an}

Karakter visual Indonesia pada iklan paling menonjol pada iklan-iklan periode 1950-an. Visual, penggambaran figur iklan banyak mengikuti figur ideal, tokoh pria digambarkan memiliki tanda-tanda seperti tokoh idola masyarakat pada saat itu, tokoh yang memproklamirkan kemerdekaan Indonesia, dan saat itu adalah euphoria lepas dari belenggu penjajahan. Figur pria digambarkan ber jas, dasi dan berkopiah, sedangkan tokoh wanita digambarkan sebagai pendamping dan penyokong pria dalam bekerja, wanita memakai kain-kebaya dengan model rambut yang disanggul. Pesan verbal dalam iklan-iklan masa itu antara lain adalah kebiasaan untuk hidup berhemat, membangun pemuda dan rakyat yang kuat dengan bahan atau hasil produksi dari bumi Indonesia nan indah. Konsep komunikasi iklan yang digunakan pada waktu itu adalah dengan pendekatan 
peragaan, yaitu untuk mengambarkan keuntungan utama dari sebuah produk atau jasa dengan memperagakannya peristiwa penggunaannya, serta pendekatan dialog, yaitu adegan pembicaraan dimana salah seorang mempunyai pertanyaan, dan orang lain menjawabnya dengan menyarankan menggunakan suatu produk, dengan benefit hemat tetapi berkualitas. Hemat menjadi topik pada masa itu, karena kurangnya pasokan barang.
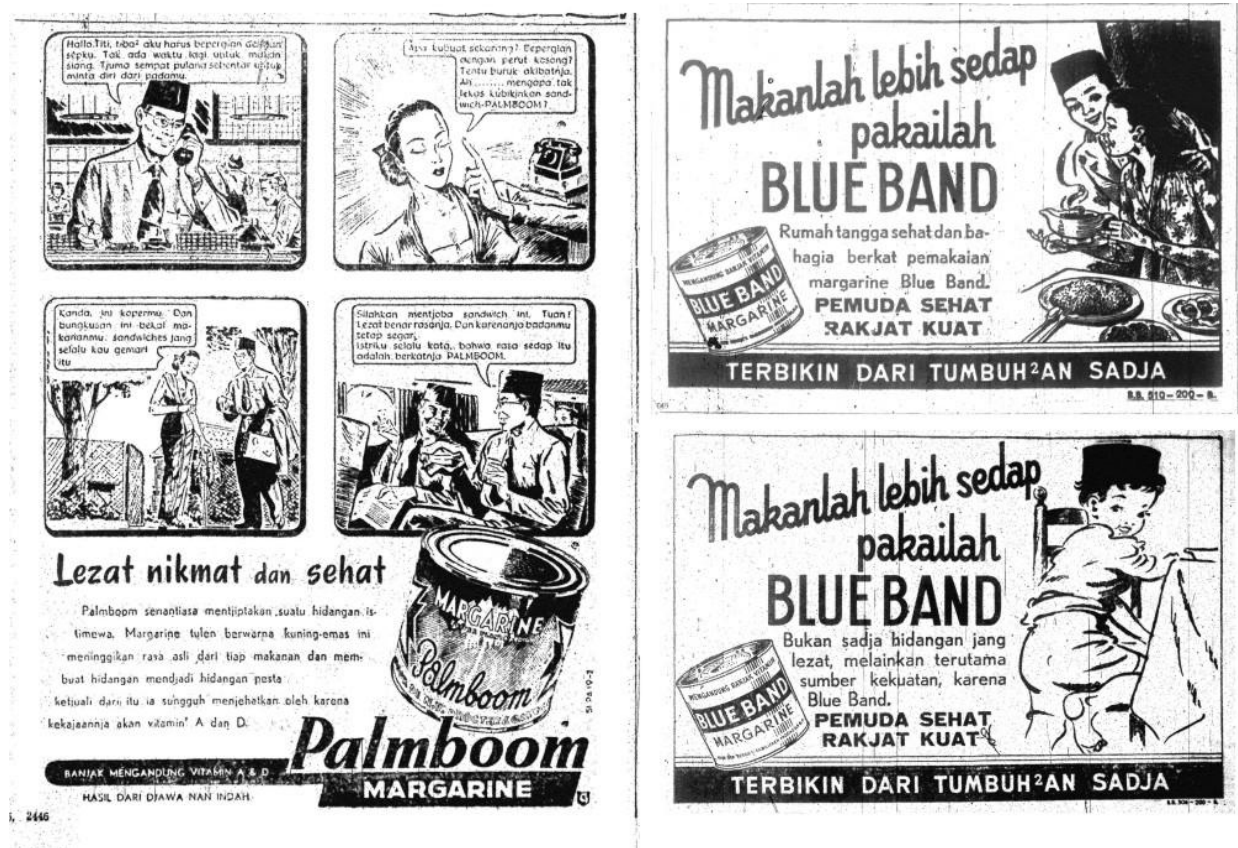

Gambar 5 Iklan cetak Tahun 1950an (Pikiran Rakjat [16]).

\subsection{Perioda Orde baru}

Barang-barang eceran yang diiklankan sekira $73 \%$ adalah produk internasional yang mengalir masuk membanjiri Indonesia produk-produk itu berupa makanan, minuman, pakaian, obat-obatan dipasarkan untuk segenap lapisan masyarakat di Indonesia, melalui jalur pemasaran yang kuat, termasuk dalam iklan. Penggambaran figur terutama wanita, bukan lagi pakaian kain dan kebaya yang menutupi aurat, melainkan celana pendek atau "hot pants" yang memamerkan paha bahkan pusar, dengan sikap tubuh yang menantangmenggiurkan. Figur wanita masih figur Indonesia yang berambut hitam. Birobiro iklan internasional dengan konsep komunikasi dan konsep kreatif yang diciptakan di negara asalnya, mentransformasi budaya western terhadap budaya Indonesia. Hasilnya adalah orang Indonesia tampil dalam iklan dengan pakaian dan perilaku seperti orang barat. 

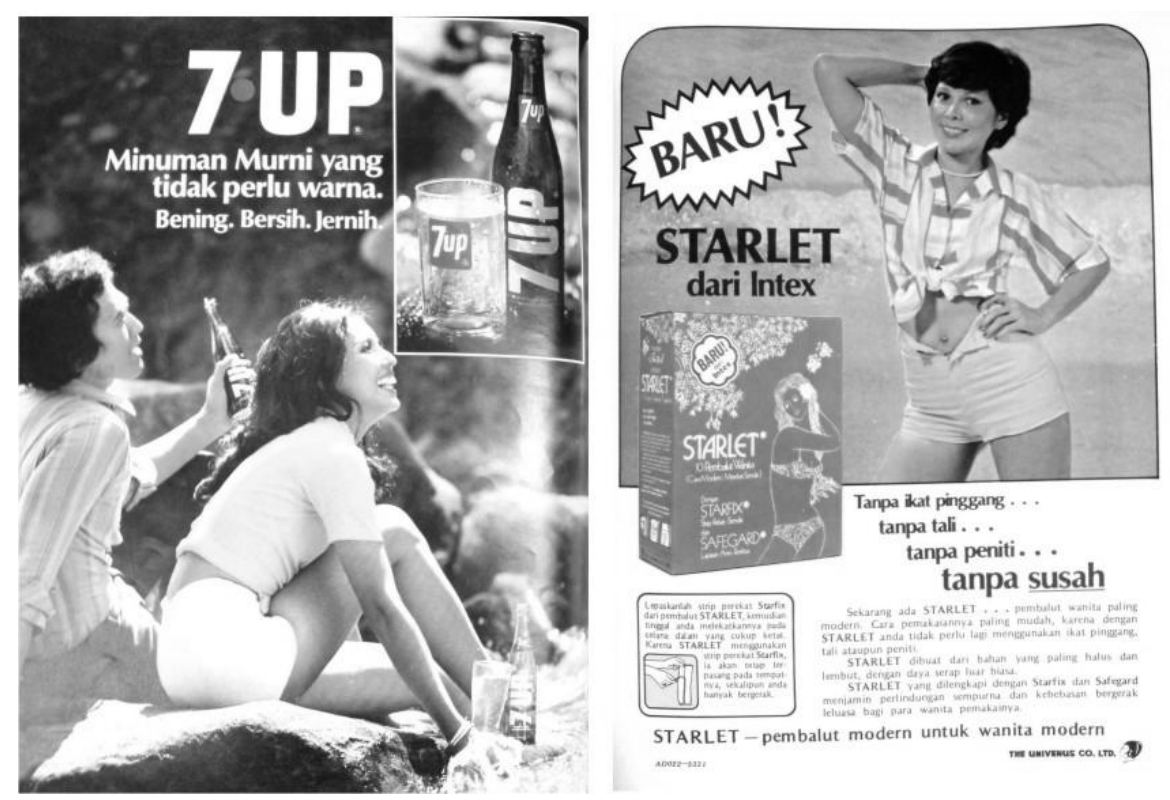

Gambar 6 Iklan cetak tahun 1970an (Majalah Kartini [17]).

\subsection{Perioda Reformasi}
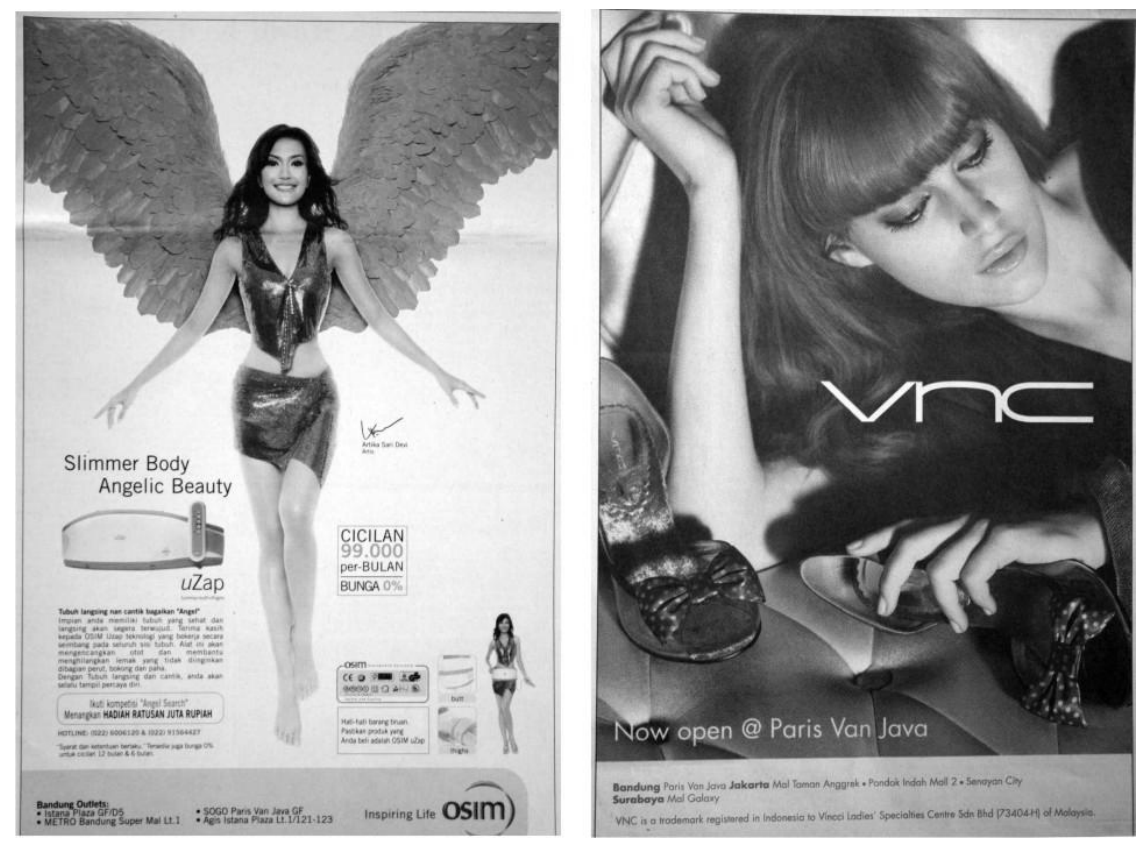

Gambar 7 Iklan cetak tahun 2000-an ( Pikiran Rakyat [18]). 
Penggambaran figur Indonesia dalam iklan menjadi semakin sedikit unsur lokalnya. Model iklan di gunakan yang berwajah Eropa, bahkan rambut di cat. Cara berpakaian dan bersikap sangat berbeda dengan iklan tahun 1950-an, untuk menggambarkan ide tentang ringan, terbang mengadopsi cerita manusia bersayap dari Yunani, bukan lagi Dewi Nawangwulan atau Gatot kaca. Teks atau copy lebih suka menggunakan bahasa Inggris untuk meraih citra yang lebih tinggi.

\section{$4 \quad$ Kesimpulan}

Indonesia sangat menarik untuk dijajah dan dijadikan target pasar. Sejak jaman kolonial Belanda, pendudukan Jepang dan setelah mendapat kemerdekaannya pun tak lepas dari penjajahan. Penjajahan model masa kini sering disebut sebagai penjajahan budaya dan ekonomi, yang ujungnya adalah profit finansial bagi negara atau industri pengekspor, dan ini adalah paham kesejagatan atau "globalisasi". Penjajahan masa kini tidak harus menggunakan serbuan tentara, melainkan serbuan melalui budaya dan gaya hidup, yang barangsiapa tidak mengikutinya akan dijuluki "kampungan" atau "jadul". Serbuan budaya melalui musik, filem dan dunia maya, yang dampaknya diantaranya adalah pada perilaku, warna rambut, idiom, bahkan bahasa dalam iklan serta pembawa acarapun mencampur-campur bahasa Indonesia dengan idiom-idiom bahasa Inggris-Amerika, bahkan lafal kata-kata bahasa Indonesiapun meniru pelafalan orang barat, yang menurutnya akan mempunyai citra yang tinggi.

Dengan menggunakan istilah pasar bebas atau globalisasi, pendekatan dan strategi kreatif iklan semakin canggih, demikian pula media yang menyebarkannya. digunakannya pendekatan gaya hidup atau "lifestyle", yang menurut Michael Belch [1] yaitu lebih menciptakan kebutuhan dari pada hanya sekedar bagaimana produk atau jasa melayani mereka, menyodorkan kepada khalayak dengan citraan tentang kehidupan yang mewah dan menyarankan untuk menambah kepemilikan materi yang dapat memuaskan dan membahagiakan serta kesenangan hidup, serta sebagai status simbol, keberhasilan serta mendapatkan pengakuan sosial sekaligus tersohor.

Secara perlahan masyarakat Indonesia mulai kehilangan jatidirinya, kebanggaan akan menggunakan produk lokal semakin menipis, kata-kata "buatan lokal" berkonotasi buruk, cepat rusak. Masyarakat semakin menyukai segala sesuatu yang berbau luar negeri, terutama Amerika. Semboyan "berdikari" semakin kabur dan ditinggalkan. Keluaran dalam iklan adalah visualisasi dari figur Indonesia dengan sikap, perilaku dan idiom "western".

Mengingatkan kita pada jaman penjajahan dahulu, banyak pribumi yang menegasikan identitas lokalnya karena ingin menjadi Belanda. 


\section{Referensi}

[1] Belch, George E \& Michael A. 1998. Advertising and Promotion, Mc Graw Hill Companies, Inc., Boston, Massachusetts.

[2] Collier, John. 1992. Visual Anthropology, University of New Mexico Press, Alburquerque.

[3] Krugman, D.M, Reid L.N., Dunn S.W. \& Barban, A.M. 1994. Advertising, The Dryden Press, Sydney.

[4] Pitaloka, Dyah. 2008. Mencari Karakter Indonesia dalam Iklan Kita, Majalah Cakram, no 2 286, hal 30.

[5] Sultan Hamengkubuwono X. 2007. Merajut Kembali Keindonesiaan Kita, Gramedia Pustaka Utama, Jakarta.

[6] Rais, Mohammad Amien. 2008. Agenda Mendesak Bangsa : Selamatkan Indonesia, Mizan \& PPSK, Yogyakarta.

[7] Kuntowijoyo. 2008. Penjelasan Sejarah (historical Explanation), Tiara Wacana, Yogyakarta

[8] Riclef, H.C. 1991. Sejarah Indonesia Moderen, Gajah Mada University Press, Yogyakarta.

[9] Setiyono, Budi. (ed.). 2004. Reka Reklame : Sejarah Periklanan Indonesia 1774-1984, Persatuan Perusahaan Periklanan Indonesia, Jakarta dan Galang Press, Yogyakarta.

[10] Riyanto, Bedjo. 2000. Iklan Surat Kabar dan Perubahan Masyarakat Di Jawa Masa Kolonial (1870-1915), Tarawang, Yogyakarta.

[11] Surjomiharjo, A., et al. 2002. Beberapa Segi Perkembangan Sejarah Pers Di Indonesia, Penerbit Buku Kompas, Jakarta.

[12] Majalah Jawa Baroe. 1943.

[13] Winarno, B. 2008. Rumah Iklan: Upaya Matari Menjadikan Periklanan Indonesia Tuan Rumah Di Negeri Sendiri, Kompas Media Nusantara, Jakarta.

[14] Setiyono, Budi. (penyunting). 2005. Cakap Kecap(1972-2003), Persatuan Perusahaan Periklanan Indonesia, Jakarta dan Galang Press, Yogyakarta.

[15] De locomotief. 1908.

[16] Koran Pikiran Rakjat. 1952. 
[17] Majalah Kartini, Agustus. 1976.

[18] Koran Pikiran Rakyat, Juli 2007. 